Revista Universo Contábil, ISSN 1809-3337

Blumenau, v. 8, n. 3, p. 40-61, jul./set., 2012

doi:10.4270/ruc.2012321

Disponível em www.furb.br/universocontabil

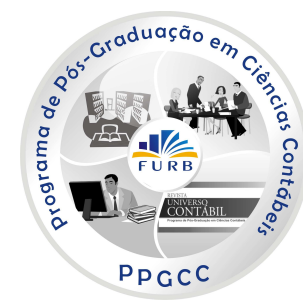

\title{
CARACTERÍSTICAS E COMPETÊNCIAS DOS CONSELHOS DE ADMINISTRAÇÃO DE BANCOS BRASILEIROS E SUA RELAÇÃO COM SEU DESEMPENHO FINANCEIRO'
}

\section{FEATURES AND POWERS OF THE BOARDS OF DIRECTORS OF BRAZILIAN BANKS AND THEIR RELATIONSHIP WITH THEIR FINANCIAL PERFORMANCE \\ CARACTERÍSTICAS Y COMPETENCIAS DE LOS CONSEJOS DE ADMINISTRACIÓN DE LOS BANCOS BRASILEÑOS Y LA RELACIÓN CON SU DESEMPEÑO FINANCIERO}

\begin{abstract}
Orleans Silva Martins
Doutorando em Ciências Contábeis pelo Programa Multiinstitucional UnB/UFPB/UFRN Endereço: Rua Farm. Antônio Leopoldo Batista, 172, Apto. 201, Jardim São Paulo CEP: 58051-110 - João Pessoa/PB - Brasil E-mail: orleansmartins@ccsa.ufpb.br Telefone: (83) 8892-4970

Lílian Perobon Mazer Doutoranda em Ciências Contábeis pelo Programa Multiinstitucional UnB/UFPB/UFRN Endereço: Rua Wagner Augusto Bezerra Japyassu, 128, 1ํandar, Centro CEP: 58500-000 - Monteiro/PB - Brasil E-mail: lilian_mazer@yahoo.com.br Telefone: (83) 8889-2515

Paulo Roberto Barbosa Lustosa Doutor em Controladoria e Contabilidade pela FEA/USP Professor do Programa de Pós-Graduação em Ciências Contábeis da UnB/UFPB/UFRN Endereço: Campus Universitário Darcy Ribeiro, Prédio da FA, 2ํㅡㄹ Andar, Asa Norte CEP: 70910-900 - Brasília/DF - Brasil E-mail: prblustosa@gmail.com Telefone: (61) 3307-2345

Edilson Paulo Doutor em Controladoria e Contabilidade pela FEA/USP Professor do Programa de Pós-Graduação em Ciências Contábeis da UnB/UFPB/UFRN Endereço: Cidade Universitária, Campus I, Departamento de Finanças e Contabilidade CEP: 58059-900 - João Pessoa/PB - Brasil E-mail: e.paulo@ccsa.ufpb.br Telefone: (83) 3216-7459
\end{abstract}

\footnotetext{
1 Artigo recebido em 30.08.2011. Revisado por pares em 24.12.2011. Reformulado em 21.05.2012. Recomendado para publicação em 23.05.2012 por Ilse Maria Beuren (Editora). Publicado em 30.07.2012. Organização responsável pelo periódico: FURB.
} 


\section{RESUMO}

Este estudo teve como objetivo identificar as principais características e competências dos conselhos de administração dos bancos brasileiros e relacioná-las com seus desempenhos financeiros. Fundamentando-se na Teoria da Agência, foi levantado um referencial acerca do conselho de administração das empresas brasileiras e de sua relação com o desempenho financeiro e a governança corporativa dessas organizações. Nesse sentido, realizou-se um estudo comparativo junto às 28 empresas integrantes do segmento Bancos da BM\&FBovespa, por meio de suas informações financeiras dos anos de 2008 e 2009. Foram coletados dados a partir de suas demonstrações financeiras, relatórios de administração, estatutos sociais e atas de assembléias gerais, os quais foram tabulados e analisados no intuito de se traçar tendências. Seus resultados sugerem que as principais características que afetam o desempenho financeiro dos bancos são: a quantidade de membros do gênero feminino que esse conselho possui, o fato de possuir representante dos empregados e membro estrangeiro e o prazo de mandato ser superior a três anos. As competências que apresentaram relações com os desempenhos financeiros das companhias foram: fiscalizar a gestão dos diretores, autorizar prestação de garantias e obrigações a terceiros e escolher e destituir auditores independentes.

Palavras-chave: Instituições financeiras. Governança corporativa. Desempenho financeiro.

\section{ABSTRACT}

This study aimed to identify the main features and powers of the boards of directors of Brazilian banks and relate them with their financial performance. Based on Agency Theory, a reference on the board of directors of Brazilian companies and of their relationship with financial performance and corporate governance of these organizations was put together. In this sense, a comparative study was conducted with 28 companies of the Banking segment of BM\&FBovespa, through their financial information for the years 2008 and 2009. Data were collected from their financial statements, administration reports, social bylaws and minutes of general meetings, which were tabulated and analyzed in order to trace trends. The results suggest that the main features that affect the financial performance of banks are: the number of female members in the board, the fact of having a representative of employees and a foreign member, and the term of office longer than three years. The powers that had relations with the financial performance of companies were: supervise the management of directors, authorize the provision of guarantees and obligations to third parties, and appoint and dismiss independent auditors.

Keywords: Financial institutions. Corporate governance. Financial performance.

\section{RESUMEN}

Este estudio tuvo como objetivo identificar las principales características y responsabilidades de las juntas directivas de los bancos brasileños, así como la relación con su desempeño financiero. Basado en la Teoría de la Agencia, fue criado en una referencia de la junta directiva de las empresas brasileñas y su relación con el desempeño financiero y el gobierno corporativo de estas organizaciones. En consecuencia, se llevó a cabo un estudio comparativo entre las 28 empresas en el segmento de Banca de BM\&FBovespa, a través de su información financiera para los años 2008 y 2009. Los datos fueron recogidos de sus estados financieros, informes de gestión, estatutos y actas de las reuniones generales, los cuales fueron tabulados y analizados a fin de rastrear las tendencias. Sus resultados sugieren que las características principales que afectan el desempeño financiero de los bancos son los siguientes: el número de mujeres miembros de este consejo tiene, el hecho de tener un 
representante de los empleados y un miembro extranjero y el mandato de más de tres años. Sin embargo, los poderes que tenían relaciones con el desempeño financiero de las empresas iban a supervisar la administración de los directores, autorizar la concesión de garantías y obligaciones a terceros, y nombrar y remover auditores independientes.

Palabras clave: Instituciones financieras. Gobierno corporativo. Desempeño financiero.

\section{INTRODUÇÃO}

Nas duas últimas décadas, crises, fraudes e problemas de gestão têm atraído a atenção dos diversos participantes dos mercados às instituições financeiras, especialmente aos bancos. Em meados de 2007, a chamada "Crise dos Subprime" assolou bancos de diferentes lugares do mundo, revelando a fragilidade do sistema financeiro internacional quanto à sua exposição aos riscos inerentes a esses mercados. Ainda, como destacado por Martins e Rodrigues (2005), os recentes escândalos éticos e financeiros de corporações americanas, como a Enron, a WorldCom e a Imclone Systems, colocaram em cheque a confiabilidade das informações contábeis, das auditorias externas e, principalmente, o papel dos conselhos de administração dessas companhias, o que tem motivando discussões sobre a governança corporativa nas empresas e a sua importância na construção de um novo arcabouço de controles internos, dotado de políticas, regras e procedimentos que assegurem aos diversos investidores lisura na maneira como a empresa é dirigida por seus gestores.

Escândalos e fraudes contábeis envolvendo instituições financeiras não são exclusividades dos Estados Unidos. No Brasil, casos como os do Banco Nacional (1995) e do Banco Santos (2004) tiveram repercussão internacional e findaram com a intervenção do Banco Central do Brasil (BCB). Recentemente, apesar de o Brasil ter sido considerado um dos países menos afetados pela Crise dos Subprime, logo após os efeitos ocasionados pela redução da credibilidade terem sido superados e o crédito disposto pelos bancos ter se restabelecido, a imprensa nacional noticiou uma fraude de $\mathrm{R} \$ 2,5$ bilhões através de seus principais jornais, como o Valor Econômico (2010), o que despertou a preocupação dos investidores quanto à confiabilidade dos procedimentos de gestão e informações financeiras divulgadas por essas organizações. $\mathrm{O}$ caso do Banco PanAmericano, $21^{\circ}$ do ranking nacional, demonstrou como uma fraude contábil, cujo objetivo era maquiar os números contábeis para garantir bônus aos executivos, pode passar despercebida aos órgãos de fiscalização, como o conselho de administração (CA), trazendo prejuízos aos detentores de capital.

Diversos meios de comunicação noticiavam a fraude e elegiam prováveis culpados. A provável razão? Melhorar artificialmente o resultado do banco para aumentar o lucro e, consequentemente, os bônus pagos à diretoria. Os prováveis culpados? Os diretores em exercício naquele momento. Todavia, também poderá ser responsabilizado o conselho de administração da empresa, uma vez que é responsável pela eleição, destituição, fixação de atribuições e supervisão do exercício dos membros da diretoria. Pois, como elucida o Regimento Interno do Conselho de Administração do Banco PanAmericano, esse conselho é o órgão de deliberação colegiada responsável pelo estabelecimento das políticas gerais de negócios, incluindo sua estratégia de longo prazo.Assim, parafraseando Silva e Magalhães Filho (2004), indubitavelmente as alternativas estratégicas escolhidas pela alta administração da empresa são, em grande parte, responsáveis pelo desempenho da organização.

Para Martins (2004), esse novo contexto internacional do mundo dos negócios tem evidenciado fatores contingenciais como a globalização, as privatizações, a competição e os grandes escândalos financeiros, os quais têm motivado as recentes alterações observadas nas estruturas de governança corporativa das companhias, principalmente no que diz respeito às definições das competências dos conselhos de administração dessas corporações. Para o autor, 
especialmente no caso do Brasil, as empresas que passaram pelo processo de desestatização foram as mais afetadas por essas alterações, devido à sua estrutura acionária. Por outro lado, Bruère, Silva e Santos (2007) observam que a atuação e, sobretudo, a composição dos conselhos de administração têm sido motivo de preocupação para a comunidade acadêmica. Ainda, no âmbito brasileiro, é pequena a produção científica sobre essa temática, especialmente aquela baseada em evidências empíricas.

Diante desse cenário, foi realizado um levantamento sobre os principais estudos que abordam o conselho de administração de companhias abertas, por meio do qual foi possível notar que, embora esse tema seja objeto de diversos estudos fora do país, no Brasil não é comum a realização de pesquisas que o abordem, principalmente relacionando-o com o desempenho financeiro das empresas. Dentre os estudos internacionais, destaca-se o de Erhardt, Werbel e Shrader (2003), que motivou esta pesquisa, onde os autores investigaram a relação existente entre o conselho de administração e o desempenho financeiro de 127 grandes empresas nos Estados Unidos. Nesse sentido, buscou-se responder ao seguinte problema de pesquisa: Qual a relação existente entre as características e competências dos conselhos de administração dos bancos brasileiros e seus desempenhos financeiros? Dessa forma, o estudo objetiva identificar as principais características e competências dos conselhos de administração dos bancos brasileiros e relacioná-las com seus desempenhos financeiros.

\section{REFERENCIAL TEÓRICO}

Segundo Jensen e Meckling (1976), as organizações são simplesmente ficções legais que servem de rede para um conjunto de relações de contratos entre indivíduos. Sendo assim, como ficção legal, ela serve como foco para um complexo processo no qual os objetivos dos indivíduos são colocados em equilíbrio dentro de uma estrutura de relações contratuais. Em uma companhia de capital aberto, onde a propriedade e o controle do capital são separados, esses indivíduos são classificados em principal e agente. Com base nisso, Jensen e Meckling (1976) definem o que eles chamam de relação de agência, derivada de uma relação contratual onde uma ou mais pessoas (o principal) contratam outra pessoa (o agente) para desempenhar algum serviço em seu interesse, o qual envolve a delegação ao agente de alguma autoridade para tomada de decisão. De acordo com os autores, se ambas as partes da relação são maximizadoras de utilidade, existe uma boa razão para acreditar que o agente não atuará sempre nos melhores interesses do principal. Disso surge o conflito de agência.

Esse tipo de conflito é abordado pela Teoria da Agência, que se apresenta como arcabouço teórico voltado para a análise das relações entre os participantes de uma firma, onde a propriedade e o controle do capital são destinados a indivíduos distintos, dando espaço à formação do conflito de interesses. Jensen e Meckling (1976) destacam que a relação entre acionistas e gestores de uma firma se enquadra na definição de uma relação de agência, com problemas associados à separação entre propriedade e controle, tratados pela Teoria dos Direitos de Propriedade, tendo em vista que os custos de agência nascem desses problemas, o que deu origem à chamada Teoria da Estrutura de Propriedade da Empresa. Sendo assim, é mister atentar para a afirmação de Coase (1937), de que no cenário econômico a observação dos pressupostos de uma teoria é essencial, tendo em vista que a utilização da palavra firma, em economia, pode ser diferente do uso desse termo pelo homem normal.

Em seu trabalho, Coase (1937) abordou a razão pela qual as organizações existem e os custos de transações econômicas relativos ao mercado e a essas firmas. Dentre esses custos, destacam-se os de agência, abordados neste estudo. Assim, é conveniente citar dois conceitos derivados da Teoria da Agência e que se relacionam à separação de propriedade e controle, que são seleção adversa e risco moral que, para Baiman (1990), surgem do relacionamento principal-agente. Na seleção adversa, o agente possui informações que, para o proprietário, são inobserváveis ou custosas de se obter. Consequentemente, os proprietários não podem 
determinar completamente se os seus interesses estão sendo tratados da melhor maneira pelas decisões dos agentes. Já o risco moral envolve situações nas quais muitas das ações dos agentes são escondidas do proprietário ou são custosas de se observar. Com isso, pode surgir o comportamento oportunista do agente. É praticamente impossível ou muito oneroso para o proprietário monitorar todas as ações do agente (BARNEY; HESTERLY, 2004).

Barney e Hesterly (2004) observam que na economia organizacional a Teoria da Agência busca compreender as causas e consequências, para a organização, do conflito de interesses entre principal e agente, pois, para os autores, essa teoria é fortemente influenciada pela Teoria dos Direitos de Propriedade. Sendo assim, ambas as teorias dariam ênfase semelhante aos problemas de assimetria de informação quando da realização de um contrato e à eficiência como principal motivo de buscar uma estrutura de governança para as transações econômicas. No ambiente corporativo, o principal é representado pelos acionistas, especialmente aqueles externos à empresa, e os agentes são os gestores que estão à frente das tomadas de decisão. Entre os dois, está o conselho de administração das empresas, cujo papel principal é orientar e fiscalizar os gestores, zelando pelos interesses dos acionistas.

Nesse sentido, Jensen e Meckling (1976) atentam que, em seu desenvolvimento original, a Teoria da Agência tem como foco a relação entre gestores e acionistas. Para Barney e Hesterly (2004), ela é utilizada para analisar o controle das companhias, incluindo questões como o papel do corpo diretivo e as compensações da alta gerência, pois os conflitos por ela tratados têm importantes efeitos em uma larga variedade de atributos organizacionais, incluindo o controle corporativo, a compensação e a estrutura organizacional. Por essas razões, este estudo se fundamenta, essencialmente, nessa teoria, buscando relacionar as características e competências dos conselhos de administração dos bancos brasileiros com seus desempenhos financeiros, tendo em vista o interesse dos acionistas.

\subsection{O Conselho de Administração e o Desempenho Financeiro}

Os sistemas formais de planejamento estratégico assumem papel essencial nas atividades de avaliação e superação das incertezas do ambiente por parte da administração. É crescente o interesse em assegurar que a empresa tenha estratégias adequadas e que elas sejam confrontadas com seu desempenho financeiro. Apesar de existirem especificidades de uma organização em relação à outra, quase que invariavelmente, o processo é dirigido a resultados e desempenho, aos seus acionistas e à comunidade financeira. A par dessa proposição, e tendo em vista que o desempenho financeiro se alinha aos interesses dos acionistas no que diz respeito à criação de valor, ele é entendido como uma função das estratégias que a empresa implementa por meio de sua gestão (SILVA; MAGALHÃES FILHO, 2004).

Nesse contexto, o desempenho financeiro da empresa está diretamente relacionado à criação de valor para os acionistas. Com base nisso, quanto melhor o desempenho de uma firma, maior tende a ser a criação de valor para seus investidores. Dessa forma, neste estudo o desempenho financeiro dos bancos é medido por meio de duas proxies, que são o Return On Assets (ROA) e o Return On Investment (ROI). A escolha dessas variáveis considera suas extensas utilizações no mercado por analistas financeiros para avaliação de desempenho financeiro (SHRADER; BLACKBURN; ILES, 1997; ERHARDT; WERBEL; SHRADER, 2003). Aliado a isso, o CA aparece como um importante ator, tendo em vista sua função de representar os acionistas dessas organizações.

Finkelstein e Hambrick (1997) delinearam duas funções essenciais para os conselhos de administração que são fortemente relacionadas com o desempenho financeiro das empresas. Em primeiro lugar, esses conselhos geralmente são os atores mais influentes na determinação da direção estratégica e nas tomadas de decisões inerentes à posição atual da organização. Em segundo, os conselhos desempenham um papel de monitoramento e supervisão que pode incluir: representar os acionistas, controlar o uso adequado da riqueza da 
organização, responder pelos riscos de aquisição, contratação e compensação e monitorar os trabalhos dos gestores de alto nível.

Na visão de Silva e Magalhães Filho (2004), o poder de decisão encontra-se alocado nas mãos dos executivos, os quais são contratados pelos proprietários, através dos conselhos de administração, que têm a finalidade principal de representar os acionistas perante os executivos. Volpin (2002) destaca que um dos papéis essenciais do CA é o de fiscalizador e avaliador do desempenho dos executivos, cujo objetivo é minimizar os conflitos de agência entre os acionistas e os executivos, tendo em vista a criação de valor para o acionista, que pode ser comprometida pela falta de independência do conselho.

Para Martins (2004), as expectativas da organização e da sociedade sobre o CA têm mudado, pois, historicamente, ele tem sido considerado pouco atuante nas corporações, apenas referendando as decisões tomadas pelos gestores para satisfação da estrutura corporativa legal. Contudo, o autor observa que o CA é o instrumento central de governança corporativa, pois, por meio dele acionistas, stakeholders, o mercado e os diversos reguladores nacionais e internacionais interagem por um complexo caminho para afetar as ações das empresas e o monitoramento de seus gestores, o que condiz com a Teoria da Agência. Por essas razões, o CA tem se tornado o foco das atuais reformas de governança corporativa.

Segundo Carter e Lorsch (2004), o CA, no contexto norte-americano, vem respondendo às pressões externas por mudanças que têm sido impostas pelo mercado. Porém, os conselhos não vêm respondendo às mudanças capazes de torná-los mais eficazes. Segundo os autores, como resultado, a maioria dos conselhos assume a condição de uma mistura de velhas e novas práticas, as quais não fornecem a melhor forma para assumir suas crescentes responsabilidades. Assim, há vagas noções de monitoramento, que podem lhes fornecer sugestões nas tomadas de decisão, mas não explicitam seu papel frente às suas responsabilidades. Destacam que esses conselhos devem considerar vários elementos em sua composição, entre eles: (i) na estrutura - seu tamanho, liderança e comitês que requerem para realizar seu papel; e, (ii) no mix da composição - a experiência, habilidades e outros atributos de cada um de seus membros. Sendo assim, este estudo parte da identificação de alguns desses atributos para relacioná-los com o desempenho financeiro das companhias analisadas.

No Brasil, a Lei $n^{\circ}$ 6.404/76 (Lei das Sociedades por Ações), por um lado, estabeleceu os parâmetros para atuação das sociedades anônimas e as competências que seus conselhos de administração devem possuir, como uma instância deliberativa nessas empresas.

Art. 142. Compete ao conselho de administração:

I - fixar a orientação geral dos negócios da companhia;

II - eleger e destituir os diretores da companhia e fixar-lhes as atribuições, observado o que a respeito dispuser o estatuto;

III - fiscalizar a gestão dos diretores, examinar, a qualquer tempo, os livros e papéis da companhia, solicitar informações sobre contratos celebrados ou em via de celebração, e quaisquer outros atos;

IV - convocar a assembléia-geral quando julgar conveniente, ou no caso do artigo 132

V - manifestar-se sobre o relatório da administração e as contas da diretoria;

VI - manifestar-se previamente sobre atos ou contratos, quando o estatuto assim o exigir;

VII - deliberar, quando autorizado pelo estatuto, sobre a emissão de ações ou de bônus de subscrição;

VIII - autorizar, se o estatuto não dispuser em contrário, a alienação de bens do ativo permanente, a constituição de ônus reais e a prestação de garantias a obrigações de terceiros;

IX - escolher e destituir os auditores independentes, se houver (BRASIL, 1976).

Por outro lado, tanto o papel do CA como dos executivos dessas companhias tem sido relatado e acompanhado por Códigos de Melhores Práticas (CMP) de governança em vários 
países do mundo. No Brasil, o Instituto Brasileiro de Governança Corporativa (IBGC) tem desenvolvido esse código e descrito as principais competências dos conselhos de administração. O CMP brasileiro, no entanto, tem se reportado à Lei $n^{\circ}$ 6.404/76 para definir as competências do CA, destacando que os conselhos devem direcionar esforços para a determinação de estratégias, a eleição e destituição de diretores, a fiscalização da gestão dos diretores e a indicação e substituição dos auditores independentes. Nesse sentido, e reputando a Monks e Minow (2001), a observação que o foco principal da governança corporativa é a atuação e a composição dos conselhos de administração, este estudo parte das competências definidas nessa Lei para relacioná-las ao desempenho financeiro das empresas.

\subsection{O Conselho de Administração e a Governança Corporativa}

Segundo o IBGC, governança corporativa é um sistema pelo qual as sociedades são dirigidas e monitoradas, envolvendo os acionistas e os cotistas, conselho de administração, diretoria, auditoria independente e conselho fiscal. As boas práticas de governança corporativa têm como finalidade aumentar o valor da companhia, facilitar seu acesso ao capital e contribuir para sua continuidade. Sendo assim, tendo em vista o crescimento do número de companhias abertas nos mercados internacionais e a dispersão de suas ações entre investidores de diferentes regiões do mundo, os participantes e reguladores dos mercados de capitais passam a desenvolver e adotar políticas, regras e procedimentos que lhes garantam lisura na maneira como uma empresa é dirigida por seus gestores.

Nesses mercados, onde a propriedade é separada do controle e o acionista transfere a responsabilidade sobre o desempenho financeiro da companhia para o gestor, a governança corporativa é vista como um instrumento auxiliar no estudo sobre as relações entre os atores envolvidos nesse processo e os objetivos pelos quais se orienta a empresa. Segundo a Teoria da Agência, essa dissociação entre propriedade e controle pode representar um problema para a empresa quando o gestor abandona o objetivo dos acionistas (que é a maximização do valor da empresa) em proveito do seu próprio objetivo (que é garantir seu resultado mantendo o equilíbrio entre seus custos e benefícios). A separação do controle e da propriedade pode originar um conflito de interesses entre acionistas e gestores, ou seja, um conflito de agência. Nesse sentido, dentre outras prerrogativas, é responsabilidade do CA orientar os negócios da empresa e coordenar sua gestão de maneira que evite esse tipo de conflito e assegure aos acionistas que os objetivos institucionais da companhia sejam alcançados.

Para Shleifer e Vishny (1997), governança corporativa é um conceito que engloba instrumentos de monitoramento e controle de empresas, cujo objetivo é reduzir o conflito de agência. Em essência, esse problema está ligado à separação entre a gestão e as finanças, ou seja, entre o controle e a propriedade. Aliado a isso, Vieira e Mendes (2006) observam que as operações das corporações no Brasil e no mundo têm enfrentado inúmeros percalços pautados na falta de transparência, na ausência de participação efetiva dos acionistas nos conselhos de administração das empresas e na construção de acordos de acionistas inadequados às partes, dentre outros fatores. Todavia, na tentativa de reduzir esses problemas, algumas bolsas de valores têm buscado alternativas que fortaleçam as boas práticas de governança corporativa nas companhias, como os níveis diferenciados da BM\&FBovespa que, no que diz respeito ao CA, trás exigências próprias sobre sua composição em cada um dos níveis diferenciados.

\subsection{Estudos Semelhantes e variáveis relacionadas ao Desempenho Financeiro}

Erhardt, Werbel e Shrader (2003) investigaram a relação entre a diversidade dos membros do conselho de administração e o desempenho financeiro de 127 grandes empresas dos Estados Unidos da América. Para isso, utilizaram como variáveis dependentes os retornos sobre o ativo e sobre o investimento e, como variáveis independentes, indicadores de 
diversidade como sexo, idade, raça e etnia dos membros. Suas análises de correlação e regressão indicaram que a diversidade está positivamente associada com esses indicadores financeiros das empresas. Sendo assim, neste estudo também foram utilizadas como proxies para o desempenho financeiro o ROA e o ROI, como variáveis dependentes, e algumas variáveis independentes utilizadas pelos autores supracitados, como: (i) quantidade de membros do conselho, (ii) o gênero dos membros, (iii) área de formação dos membros e (iv) seu estado civil.

Berghe e Levrau (2004) buscaram identificar os elementos que constituem um bom conselho de administração, baseando-se em uma comparação entre a literatura acadêmica, os sistemas de avaliação de governança corporativa e uma pesquisa de campo realizada pelos autores sobre as práticas desse conselho, através dos pontos de vista dos administradores. Em seus resultados, observaram que as investigações acadêmicas tradicionais estão focadas em um número limitado de características quantificáveis dos conselhos de administração, enquanto profissionais atribuem maior importância a outros elementos, mais suaves, que são quase inexistentes na literatura e nas avaliações dos sistemas de governança corporativa. Nesse sentido, os autores destacam a necessidade de um melhor entendimento de todos esses elementos que determinam a eficácia do conselho.

Murphy e Mclntyre (2007) realizaram um estudo sobre o conselho de administração, interligando a literatura sobre dinâmicas de grupos à literatura sobre governança, a partir do qual propuseram um modelo conceitual destinado a avaliar o desempenho do conselho de administração, classificando o desempenho desse conselho como sendo um contributo ao desempenho da empresa como um todo. Para os autores, esse conselho é um tipo de equipe que compartilha características semelhantes a qualquer outro tipo de equipe de trabalho, o que faz com que os fatores que as levam à eficácia sejam os mesmos identificados nas demais equipes. Por fim, abordam o papel de condução que o conselho de administração deveria ser capaz de desenvolver, não se limitando a ser um simples instrumento de coerção. Com base nisso, fortaleceu-se a relação estabelecida neste estudo entre o CA e o desempenho financeiro das empresas, relacionando-o às características desses conselhos. Isso é reforçado por Martins e Rodrigues (2005), ao observarem que atribuições como as características dos conselhos afetam o desempenho da firma.

Mclntyre e Murphy (2008) caracterizaram o papel do conselho de administração de uma forma mais específica do que vinha sendo feito anteriormente, destacando seu papel de condutor da gestão da empresa. Assim, além do importante papel de supervisor da gestão, ele participa da definição das estratégias de gestão e funciona como agente negociador entre a gestão e os provedores de capital (acionistas). Sob uma visão holística, o conselho possui um papel complexo, pois está sujeito à possibilidade de agir em interesse próprio, assim como em interesse da administração, o que trás consigo a necessidade de assegurar aos acionistas que o conselho não se envolva com esse tipo de comportamento. Nesse sentido, partindo de um modelo conceitual desenvolvido pelos próprios autores, eles propõem uma lista de pequenos itens presentes nos relatórios, por meio dos quais é possível analisar o desempenho do conselho sob uma perspectiva de dinâmica de grupo.

Pugliese et al. (2009) destacam que nas últimas quatro décadas a investigação sobre a relação entre o conselho de administração e as decisões estratégicas tem se proliferado no mundo. Entretanto, observam que até o momento da realização de sua pesquisa havia pouca concordância teórica e empírica sobre a verdadeira contribuição desse conselho para a estratégia das empresas. Sendo assim, realizaram uma revisão de conteúdo em 150 artigos publicados em 27 periódicos da área de gestão até 2007, na busca de identificar a evolução dessas investigações ao longo do tempo. Em seus resultados, puderam observar que esse tipo de pesquisa tem passado de abordagens normativas e estruturais para abordagens cognitivas e comportamentais. Ainda, sugerem futuros estudos que examinem o impacto de fatores 
institucionais e contextuais sobre a contribuição esperada do CA à estratégia da empresa, o que, em parte, se busca fazer neste estudo.

Nielsen e Huse (2010) destacam que o aumento da atenção destinada às mulheres que compõem os conselhos de empresas tem apresentado novos desafios às pesquisas relativas à governança nessas empresas. Nesse sentido, os autores investigaram a contribuição das mulheres aos conselhos de administração de 201 empresas norueguesas. Para isso, fundamentaram-se nas teorias das diferenças dos gêneros para concluir que a proporção de mulheres na gestão está direta e positivamente associada ao controle estratégico do conselho. Ainda, constataram os efeitos positivos que a presença das mulheres na diretoria provoca sobre a eficácia do conselho, o que pode ser comprovado por meio do aumento das atividades desenvolvidas e da diminuição do nível de conflitos dentro do conselho. Sendo assim, com base em Nielsen e Huse (2010), foram relacionadas ao desempenho financeiro da empresa as variáveis: (i) quantidade de membros do gênero feminino e (ii) a presença de uma mulher na presidência desse conselho.

No Brasil, Bruère, Silva e Santos (2007) realizaram pesquisa junto a 434 membros dos conselhos de administração de 61 companhias dos setores de Alimentos \& Bebidas e Energia Elétrica buscando identificar a forma de composição desses conselhos no ano de 2004. Em seus resultados observaram uma expressiva predominância do gênero masculino $(91,9 \%)$ entre seus conselheiros e que as mulheres possuíam média de idade bastante inferior aos homens. Outra constatação feita pelos autores diz respeito à preferência das companhias pelos profissionais egressos de universidades localizadas no Sudeste do Brasil, especialmente aquelas do Estado de São Paulo, registrando-se a maior frequência de conselheiros oriundos de cursos de graduação da Universidade de São Paulo.

Tendo em vista as observações de Murphy e Mclntyre (2007), de que o desempenho do CA é uma contribuição ao desempenho da empresa, de Anderson, Sattar e Reeb (2004), de que as características do comitê de auditoria do conselho de administração impactam o desempenho da empresa, e de Erhardt, Werbel e Shrader (2003), que identificaram relação entre o desempenho financeiro das empresas e as características de seus conselhos, foram relacionadas ao desempenho dos bancos as seguintes variáveis investigadas por Bruère, Silva e Santos (2007): (i) quantidade de membros do gênero feminino; (ii) presença de uma mulher na presidência desse conselho e (iii) área de formação dos membros.

No que diz respeito à seleção das variáveis independentes, na literatura há evidências que indicam a relação das características do CA com sua eficiência e o desempenho das companhias. Para Lipton e Lorsh (1992) e Jensen (1993), uma característica fundamental para a eficiência de um CA está relacionada com a quantidade de membros que o compõe. Para os autores, na medida em que essa quantidade aumenta, sua eficiência diminui. Conselhos numerosos podem favorecer o surgimento de conflitos internos, em virtude de uma possível dificuldade de chegarem a um consenso nas decisões. Jensen (1993) afirma que a presença de membros independentes, externos à empresa, é essencial para o CA desempenhar seu papel de maneira eficiente. Isso é ratificado por Dutra e Saito (2002) e Moura e Beuren (2011).

Ainda no que diz respeito às características do CA que podem estar relacionadas ao desempenho financeiro da firma, Dutra e Saito (2002) destacam a presença de membro representante dos empregados, denominando-o como conselheiro afiliado. Martins e Rodrigues (2005) destacam alguns papéis do CA, segundo aspectos relevantes de suas características, que podem afetar esse desempenho, entre eles: (i) o prazo ideal de gestão e (ii) a presença de membro estrangeiro. A Lei $\mathrm{n}^{\circ}$ 6.404/76, em seu art. 142, elenca 11 competências dos conselhos de administração das companhias de capital aberto no Brasil.

\section{PROCEDIMENTOS METODOLÓGICOS}

O cuidado ao escolher um método representa o desejo de se ter procedimentos e 
caminhos seguros para alcançar ou produzir um conhecimento (KÖCHE, 1997). Assim apresenta-se a amostra e a forma de coleta dos dados, além das variáveis independentes e do modelo regressivo utilizado para relacioná-las com o desempenho financeiro das empresas.

\subsection{Amostra e Coleta dos Dados}

Para a realização do estudo foi estabelecida uma amostra composta pelos 28 bancos integrantes do segmento Bancos da Bolsa de Valores de São Paulo (BM\&FBovespa), em 10 de novembro de 2010, conforme Quadro1.

\begin{tabular}{|l|l|l|l|}
\hline \multicolumn{2}{|c|}{ Bancos Investigados } \\
\hline ABC Brasil & Banrisul & Daycoval & PanAmericano \\
Alfa Holding & Bicbanco & Indusval & Paraná \\
Alfa Investimento & Bradesco & Itaúsa & Patagônia \\
Amazônia & Brasil & Itau-Unibanco & Pine \\
Banese & BRB & Mercantil de Investimentos & Santander \\
Banestes & Consórcio Alfa & Mercantil do Brasil & Sofisa \\
Banpará & Cruzeiro do Sul & Nordeste & Votorantim \\
\hline
\end{tabular}

Quadro 1 - Bancos integrantes da amostra investigada

Os dados foram coletados nas demonstrações financeiras e nos relatórios de administração dos exercícios sociais de 2008 e 2009, além do estatuto social e das atas das assembléias gerais que elegeram e deram posse ao conselho de administração de cada banco. Esses documentos foram obtidos por meio do sítio de cada companhia, na seção de relacionamento com investidores (RI) e no programa de Divulgação Externa (DIVEXT) da BM\&FBovespa. Decidiu-se pela investigação de apenas dois exercícios sociais devido à aprovação da Lei $\mathrm{n}^{\circ}$ 11.638, em 2007, que trouxe algumas alterações à estrutura das demonstrações financeiras das empresas, podendo provocar distorções na comparação entre resultados anteriores e posteriores à sua aprovação. Foi obtido um total de 1.176 observações, relativas às 21 variáveis de 28 empresas durante dois exercícios sociais, as quais foram tabuladas e analisadas com o auxílio de planilhas eletrônicas e softwares estatísticos.

\subsection{Definição das Variáveis e Análise de Regressão}

Para o estabelecimento das relações existentes entre as características e competências do conselho de administração com o desempenho financeiro das empresas, foi realizada uma análise de regressão múltipla, a qual tem como objetivo produzir, por meio de um conjunto de observações, um modelo que permita explicar (ou presumir) a relação existente. De forma similar a Erhardt, Werbel e Shrader (2003), utilizou-se uma equação de uma reta linear, que permite estimar o valor de uma variável dependente $(\mathrm{Y})$ em função de outras variáveis independentes (X) (GUJARATI, 2006), conforme Equação 1.

$$
Y_{i}=\beta_{1}+\beta_{2} X_{i i}+\beta_{3} X_{3 i}+\mu_{i}
$$

Onde $Y_{i}$ é a variável dependente, $\beta_{1}$ a constante, $\beta_{2 \ldots n}$ os parâmetros, $X_{1}$ e $X_{2}$ as variáveis explicativas, $i$ a í-ésima observação e $\mu_{i}$ o termo de erro estocástico.

Foram utilizados dois indicadores de rentabilidade como proxies do desempenho financeiro. O primeiro deles foi o Retorno Sobre o Ativo (ROA) e o segundo o Retorno Sobre o Investimento (ROI), os quais foram calculados de acordo com as Equações 2 e 3, respectivamente, com base em Assaf Neto (2007). Assim, a escolha desses indicadores é consistente com outros estudos sobre desempenho (SHRADER; BLACKBURN; ILES, 1997; ERHARDT; WERBEL; SHRADER, 2003), além de eles serem frequentemente utilizados no mercado por analistas financeiros para avaliar o desempenho financeiro das empresas. Dessa forma, foram estimadas duas regressões, na forma robusta, com estimadores eficientes, uma tendo o ROA como variável dependente e a outra tendo o ROI. 


$$
\begin{gathered}
R O A=\frac{L O}{A T} \times 100 \\
R O T=\frac{L O}{P O+P L} \times 100
\end{gathered}
$$

Onde $L O$ é o lucro operacional do período, $A T$ é o ativo total no final do período, $P O$ é o total de passivos onerosos e $P L$ o saldo final do patrimônio líquido no final do período. Neste estudo, passivos onerosos foram aqueles efetivamente investidos na empresa por seus credores ou acionistas. Para encontrá-los, com base em Assaf Neto (2007), foram excluídos do exigível total os passivos de funcionamento, ou seja, aqueles que não são onerosos (como salários, encargos sociais, fornecedores, impostos, tarifas públicas, dividendos etc.).

As regressões foram estimadas a partir da utilização de variáveis binárias, dummies, as quais indicam a relação entre as variáveis por meio de sua presença (1) ou ausência (0) (GUJARATI, 2006). Com isso, para a estimação das equações, foram definidas as variáveis representativas das principais características dos conselhos de administração dos bancos a partir da literatura existente e da Lei das Sociedades por Ações. Dessa forma, chegou-se a

\begin{tabular}{|c|c|c|}
\hline Características & Valores & Referência \\
\hline $\begin{array}{l}\text { (A) Quantidade de } \\
\text { membros }\end{array}$ & Valores contínuos & $\begin{array}{l}\text { Lipton e Lorsh (1992); Jensen } \\
\text { (1993); Erhardt, Werbel e Shrader } \\
\text { (2003). }\end{array}$ \\
\hline $\begin{array}{l}\text { (B) Quantidade de } \\
\text { membros do } \\
\text { gênero feminino }\end{array}$ & Valores contínuos & $\begin{array}{l}\text { Erhardt, Werbel e Shrader (2003); } \\
\text { Martins e Rodrigues (2005); } \\
\text { Bruère, Silva e Santos (2007); } \\
\text { Nielsen e Huse (2010). }\end{array}$ \\
\hline $\begin{array}{l}\text { (C) Possui membro } \\
\text { do gênero } \\
\text { feminino na } \\
\text { presidência }\end{array}$ & $\begin{array}{l}\text { Assume valor } 1 \text { quando o conselho for } \\
\text { presidido por uma mulher, e valor } 0 \text { quando } \\
\text { presidido por homem }\end{array}$ & $\begin{array}{l}\text { Bruère, Silva e Santos (2007); } \\
\text { Martins e Rodrigues (2005); } \\
\text { Nielsen e Huse (2010). }\end{array}$ \\
\hline $\begin{array}{l}\text { (D) Possui membro } \\
\text { independente }\end{array}$ & $\begin{array}{l}\text { Assume valor } 1 \text { quando existir, pelo menos, } \\
\text { um membro independente no conselho, e valor } \\
0 \text { caso contrário }\end{array}$ & $\begin{array}{l}\text { Jensen (1993); Dutra e Saito } \\
\text { (2002); Martins e Rodrigues } \\
\text { (2005); Moura e Beuren (2011). }\end{array}$ \\
\hline $\begin{array}{l}\text { (E) Possui membro } \\
\text { representante dos } \\
\text { empregados }\end{array}$ & $\begin{array}{l}\text { Assume valor } 1 \text { quando existir, pelo menos, } \\
\text { um representante dos empregados no conselho, } \\
\text { e valor } 0 \text { quando não existir nenhum }\end{array}$ & Dutra e Saito (2002). \\
\hline $\begin{array}{l}\text { (F) Possui membro } \\
\text { estrangeiro }\end{array}$ & $\begin{array}{l}\text { Assume valor } 1 \text { quando existir, pelo menos, } \\
\text { um membro estrangeiro no conselho, e valor } 0 \\
\text { quando não existir nenhum }\end{array}$ & Martins e Rodrigues (2005). \\
\hline $\begin{array}{l}\text { (G) O prazo máximo } \\
\text { de gestão é três } \\
\text { anos }\end{array}$ & $\begin{array}{l}\text { Assume valor } 1 \text { quando o prazo de gestão do } \\
\text { inferior ou igual a três anos, e valor } 0 \text { quando } \\
\text { maior que três }\end{array}$ & Martins e Rodrigues (2005). \\
\hline $\begin{array}{l}\text { (H) A maioria dos } \\
\text { membros possui } \\
\text { graduação na área } \\
\text { de negócios }\end{array}$ & $\begin{array}{l}\text { Assume valor } 1 \text { quando a maioria dos } \\
\text { membros for graduada em Administração, } \\
\text { Economia ou Contabilidade, e valor } 0 \text { quando } \\
\text { em qualquer outro curso }\end{array}$ & $\begin{array}{l}\text { Erhardt, Werbel e Shrader (2003); } \\
\text { Martins e Rodrigues (2005); } \\
\text { Bruère, Silva e Santos (2007). }\end{array}$ \\
\hline $\begin{array}{l}\text { (I) } \text { O estado civil } \\
\text { mais comum } \\
\text { entre os membros } \\
\text { é casado }\end{array}$ & $\begin{array}{l}\text { Assume valor } 1 \text { quando a maioria dos } \\
\text { membros for representada por casados, e valor } \\
0 \text { caso contrário }\end{array}$ & Erhardt, Werbel e Shrader (2003). \\
\hline
\end{tabular}
nove variáveis, as quais são expostas no Quadro 2.

Quadro 2 - Variáveis independentes referentes às características do conselho de administração

Ainda, considerando que a Lei das S/A contém em seu texto as competências que o conselho de administração deve possuir e, não obstante, condiciona o cumprimento de algumas dessas competências ao seu tratamento no estatuto social de cada companhia, foram elencadas 11 competências, conforme art. 142 da referida Lei, conforme Quadro 3. 


\begin{tabular}{|l|l|}
\hline \multicolumn{1}{|c|}{ Competências } & \multicolumn{1}{|c|}{ Referência } \\
\hline (J) Fixa a orientação geral dos negócios da companhia & Art. 142, I \\
\hline (K) Elege e destitui os diretores da companhia, fixando-lhes atribuições conforme estatuto & Art. 142, II \\
\hline (L) Fiscaliza a gestão dos diretores, examinando a qualquer tempo suas ações & Art. 142, III \\
\hline (M) Convoca a assembléia geral & Art. 142, IV \\
\hline (N) Emite parecer sobre o relatório de administração e contas da diretoria & Art. 142, V \\
\hline (O) Emite parecer previamente sobre atos e contratos & Art. 142, VI \\
\hline (P) Delibera sobre a emissão de ações ou de bônus de subscrição & Art. 142, VII \\
\hline (Q) Autoriza a alienação de bens do ativo não circulante & Art. 142, VIII \\
\hline (R) Autoriza a constituição de ônus reais & Art. 142, VIII \\
\hline (S) Autoriza a prestação de garantias e obrigações a terceiros & Art. 142, VIII \\
\hline (T) Escolhe e destitui os auditores independentes & Art. 142, IX \\
\hline
\end{tabular}

Quadro 3 - Variáveis independentes referentes às competências do conselho de administração Fonte: Brasil (1976, Art. 142).

$\mathrm{Na}$ análise de regressão, cada variável (competência) assume valor 1 quando essa competência é determinada no estatuto social da companhia, e valor 0 quando não o for. Sendo assim, a equação funcional da variável dependente $\left(\mathrm{Y}_{i}\right)$, ROA ou ROI, foi estimada conforme Equação 4. As demais variáveis, independentes, estão expostas nos Quadros 2 e 3, e $\mu_{i}$ representa o erro estocástico da equação.

$Y_{i}=\beta_{1}+\beta_{2} A_{1 i}+\beta_{3} E_{1 i}+\beta_{4} C_{1 i}+\beta_{5} D_{1 i}+\beta_{6} E_{1 i}+\beta_{7} F_{1 i}+\beta_{3} G_{1 i}+\beta_{9} H_{1 i}+\beta_{10} I_{1 i}+\beta_{11} J_{1 i}+\beta_{12} K_{1 i}$ $+\beta_{13} Z_{1 i}+\beta_{14} M_{1 i}+\beta_{15} N_{1 i}+\beta_{16} O_{1 i}+\beta_{17} R_{1 i}+\beta_{18} Q_{1 i}+\beta_{19} R_{1 i}+\beta_{20} S_{1 i}+\beta_{21} T_{1 i}+\beta_{2 i} U_{1 i}+\mu_{i}$

Por fim, para determinação dos testes estatísticos a serem utilizados, foi realizado o teste de normalidade de Jarque-Bera, que indicou a existência de distribuição normal. Assim, para verificar se as regressões estimadas não eram espúrias, foram analisadas a existência de autocorrelação, de heterocedasticidade, a significância da regressão e seu coeficiente de determinação, todos a um nível de significância de 95\%, com base nos valores de referência apresentados por Gujarati (2006). Com isso, verificou-se que as regressões não são espúrias.

\section{RESULTADOS}

A análise e a discussão dos resultados foram organizadas em duas etapas. Na primeira, é apresentada a análise descritiva dos resultados. Na segunda, apresentam-se as relações entre as proxies de desempenho financeiro das firmas e suas características e competências.

\subsection{Descrição das Características e Competências}

Por meio da investigação das principais características dos conselhos de administração dos bancos brasileiros, pode-se observar que, em média, os conselhos possuem 6,7 membros, número que representa mais que o dobro da quantidade mínima exigida pela Lei das S/A. O banco que apresentou maior número de membros foi o Itaú-Unibanco, com 13, e o menor foi o Alfa Holding, com 3. Ressalte-se, ainda, que apenas esse banco possui o número mínimo exigido pela referida Lei e as quantidades de membros mais frequentes são 6 e 9 membros, observadas em seis bancos cada uma. A Tabela 1 detalha esses resultados por gênero.

Tabela 1 - Quantidade de conselheiros dos bancos, por gênero. 2008 - 2009

\begin{tabular}{c|c|c|c|c}
\hline Conselheiros & Média & Mínimo & Máximo & Moda \\
\hline Homens & 6,32 & 3 & 13 & 6 e 9 \\
Mulheres & 0,39 & 0 & 2 & 0 \\
\hline Geral & $\mathbf{6 , 7 1}$ & $\mathbf{3}$ & $\mathbf{1 3}$ & 6 e 9 \\
\hline
\end{tabular}

A presença feminina nos conselhos de administração dos bancos brasileiros ainda é 
pouco frequente. Dos 28 bancos, apenas 10 possuem mulheres entre seus membros. Um banco possui duas mulheres, os demais nove possuem apenas uma. Destaca-se, entretanto, o banco PanAmericano, único a possuir uma mulher presidindo seu CA. Constata-se que as mulheres representam cerca de 5,9\% de um total de 188 membros dos CA dessas empresas, contra $94,1 \%$ de homens. Com isso, nota-se que esse ainda é um cargo predominantemente masculino, assim como constatou Bruère, Silva e Santos (2007) junto a 434 membros dos conselhos de administração de 61 empresas listadas nos setores de Alimentos \& Bebidas e Energia Elétrica da BM\&FBovespa, onde 91,9\% deles era do gênero masculino.

A Tabela 2 detalha os tipos de membros observados nos bancos: independente, representante dos empregados e estrangeiro. Dentre as 28 empresas, conforme as atas das assembleias que elegeram seus membros, apenas 13 bancos possuem membros independentes. Essa é uma exigência do Regulamento de Práticas Diferenciadas de Governança Corporativa da BM\&FBovespa para as empresas listadas no Novo Mercado e no Nível 2. Nesses níveis se encontram listados apenas 4 bancos. Outros 17 estão listados em outros níveis e 7 não estão listados. Talvez essa seja uma explicação para a existência de membros independentes em apenas 13 empresas. Duas empresas possuem membros representantes dos empregados e oito têm membros estrangeiros, principalmente oriundos dos Estados Unidos, Espanha e Portugal.

Tabela 2 - Tipos de conselheiros e quantidade de bancos que os possuem. 2008 - 2009

\begin{tabular}{c|c|c}
\hline Tipos de Conselheiros & $\mathbf{N}^{\mathbf{0}}$ de Bancos & \% \\
\hline Independente & 13 & 46,4 \\
Representante & 2 & 7,1 \\
Estrangeiro & 8 & 28,6 \\
\hline
\end{tabular}

O prazo médio de gestão dos eleitos para integrar tais conselhos é inferior a três anos, conforme determina a Lei das S/A. Os prazos mais comuns dos mandatos são 1 e 2 anos. Ressalta-se, entretanto, que apesar de a legislação exigir que o prazo máximo seja três anos, pode-se observar que 2 bancos apresentam membros eleitos por períodos superiores ao limite, além de não terem sido encontrados indícios de reeleição, como permite a legislação.

Com relação ao perfil pessoal, verificou-se que a maioria dos conselheiros é formada por casados. Quanto ao perfil profissional, a maioria é de graduados em cursos fora da área de negócios $(14,4 \%$ nas diversas Engenharias, $8,0 \%$ em Direito e 35,0\% em outros cursos não relacionados), como pode ser observado na Tabela 3.

Tabela 3 - Profissões dos conselheiros dos bancos. 2008 - 2009

\begin{tabular}{c|c|c}
\hline Profissões & N & \% \\
\hline Economia & 47 & 25,0 \\
Engenharias & 27 & 14,4 \\
Administração & 25 & 13,3 \\
Direito & 15 & 8,0 \\
Contabilidade & 8 & 4,3 \\
Outros & 66 & 35,0 \\
\hline Total & $\mathbf{1 8 8}$ & $\mathbf{1 0 0 , 0}$ \\
\hline
\end{tabular}

As profissões mais comuns entre os conselheiros são: Economia (25,0\%), Engenharias diversas $(14,4 \%)$, Administração (13,3\%), Direito (8,0\%), Contabilidade (4,3\%) e Outros $(35,0 \%)$. Nota-se que os cursos da área de negócio representam, em conjunto, 42,6\% dos profissionais que atuam nos conselhos de administração dos bancos brasileiros. Em um estudo semelhante nos setores de Alimentos \& Bebidas e Energia Elétrica da BM\&FBovespa, Bruère, Silva e Santos (2007) observaram que as profissões mais frequentes eram: Engenharias (35,9\%), Direito $(17,7 \%)$, Administração $(16,8 \%)$, Economia $(16,1 \%)$, 
Contabilidade $(5,2 \%)$ e as demais profissões em conjunto $(8,3 \%)$.

Comparando os resultados deste estudo aos dos autores supracitados, nota-se que as Engenharias continuam representando uma parcela bastante significativa dos profissionais envolvidos na gestão das companhias abertas no Brasil e que os profissionais de Administração e Contabilidade continuam representando cerca de $15 \%$ e 5\%, devidamente, dos membros desses conselhos. Ainda, comparando os resultados desses estudos no que diz respeito à profissão com maior representatividade, observa-se neste estudo que Economia é a profissão mais comum (com 25,0\%), ao passo que no estudo de Bruère, Silva e Santos (2007) havia predomínio das Engenharias (35,9\%) e Economia surgia na quarta posição $(16,1 \%)$.

Quanto às competências atribuídas aos CA, constata-se certa diversidade no que diz respeito ao que determina o estatuto social de cada instituição. Do total de 28 bancos, apenas 2 retratam em seus estatutos, entre outras atribuições, as 11 competências elencadas a partir da Lei das S/A. As competências mais citadas nos estatutos são relativas a: (i) escolha e destituição dos auditores independentes ; (ii) fixação e orientação dos negócios da companhia; (iii) eleição e destituição dos diretores; (iv) convocação da assembléia geral; e, (v) emissão de parecer sobre o relatório de administração e contas da diretoria; nesta ordem. Contudo, algumas dessas competências são facultadas às organizações, como no caso das variáveis $\mathrm{O}$, $\mathrm{P}, \mathrm{Q}, \mathrm{R}$ e S. Talvez por esse motivo essas sejam as competências com menores frequências nos estatutos. A menos citada é a referente à autorização e prestação de garantias e obrigações a terceiros (S). Entretanto, as seções referentes ao CA dos estatutos sociais desses bancos, em geral, não se limitam às competências referendadas na Lei das S/A. Na maioria dos casos as competências se adéquam às características do banco e dos negócios que ele pratica.

\subsection{Relações Existentes Entre as Variáveis}

Para investigar as relações existentes entre as variáveis representativas das características e competências atribuídas aos conselhos de administração dos bancos com seus desempenhos financeiros, de forma similar ao estudo de Erhardt, Werbel e Shrader (2003), foram estimadas duas regressões múltiplas. A primeira relacionou tais variáveis independentes com o Retorno Sobre o Ativo (ROA) dessas instituições e, a segunda, com seus Retornos Sobre o Investimento (ROI).

Para assegurar que a regressão não seja espúria, foram examinadas a existência de autocorrelação e de heterocedasticidade, além da significância e do coeficiente de determinação da regressão. Não foi observada presença de autocorrelação entre os resíduos, pois o teste de Durbin-Watson revelou valor igual a 2,095, não excedendo os limites préestabelecidos (inferior de 1,54 e superior de 2,46); a hipótese nula de não existência de heterocedasticidade do teste de White não foi rejeitada, tendo como valor crítico 34,170; a hipótese nula de não significância do modelo de regressão foi rejeitada, pois o valor crítico de F $(1,840)$ foi ultrapassado $(1,930)$, inferindo que o modelo é significante estatisticamente; e, a regressão apresentou um significativo coeficiente de determinação $(0,724)$, indicando que as variações das variáveis independentes contidas no modelo podem explicar $72,4 \%$ das variações observadas na variável dependente (ROA).

A partir dos resultados da primeira regressão, pode-se observar que 6 das 21 variáveis apresentaram significância estatística a 5\%, indicando influência sobre as variações observadas no ROA dos Bancos. As quatro primeiras são variáveis referentes às características dos conselhos: (i) quantidade de membros do gênero feminino, (ii) possui membro estrangeiro, (iii) prazo máximo de gestão de três anos e (iv) a maioria dos membros possui graduação na área de negócios. As duas últimas variáveis significantes referem-se às competências atribuídas aos conselhos: (v) autoriza a prestação de garantias e obrigações a terceiros e (vi) escolhe e destitui os auditores independentes. Além disso, a variável possui graduação na área de negócios $(\mathrm{H})$ foi significante a 10\%, conforme Tabela 4. 
Tabela 4 - Resultado da regressão linear para a variável dependente ROA. 2008 - 2009

\begin{tabular}{|c|c|c|c|c|}
\hline Variáveis & $\begin{array}{c}\text { Coeficiente } \\
\text { B } \\
\end{array}$ & $\begin{array}{c}\text { Erro } \\
\text { Padrão }\end{array}$ & $\begin{array}{c}\text { Estatística } \\
\mathbf{t} \\
\end{array}$ & $\begin{array}{c}\text { Signifi- } \\
\text { cância }\end{array}$ \\
\hline (Constant) & 0,157 & 0,050 & 3,129 & 0,004 \\
\hline (A) Quantidade de membros & 0,002 & 0,002 & 0,877 & 0,386 \\
\hline (B) Quantidade de membros do gênero feminino & $-0,015$ & 0,007 & $-2,077$ & $* 0,047$ \\
\hline (C) Possui membro do gênero feminino na presidência & $-0,021$ & 0,017 & $-1,263$ & 0,215 \\
\hline (D) Possui membro independente & $-0,002$ & 0,025 & $-0,100$ & 0,921 \\
\hline (E) Possui membro representante dos empregados & $-0,024$ & 0,011 & $-2,066$ & $* 0,046$ \\
\hline (F) Possui membro estrangeiro & $-0,047$ & 0,023 & $-2,072$ & $* 0,046$ \\
\hline (G) O prazo máximo de gestão é 3 (três) anos & $-0,034$ & 0,016 & $-2,110$ & $* 0,042$ \\
\hline (H) A maioria dos membros possui graduação na área & 0,028 & 0,016 & 1,724 & $* * 0,093$ \\
\hline (I) O estado civil mais comum entre os membros & 0,029 & 0,021 & 1,392 & 0,173 \\
\hline (J) Fixa a orientação geral dos negócios da companhia & 0,008 & 0,016 & 0,492 & 0,626 \\
\hline (K) Elege e destitui os diretores da companhia & $-0,010$ & 0,016 & $-0,621$ & 0,539 \\
\hline (L) Fiscaliza a gestão dos diretores & $-0,010$ & 0,008 & $-1,277$ & 0,210 \\
\hline (M) Convoca a assembléia geral & $-0,012$ & 0,015 & $-0,791$ & 0,434 \\
\hline (N) Emite parecer sobre o relatório de administração & $-0,019$ & 0,014 & $-1,314$ & 0,197 \\
\hline (O) Emite parecer previamente sobre atos e contratos & 0,011 & 0,009 & 1,274 & 0,211 \\
\hline (P) Delibera sobre a emissão de ações ou de bônus & 0,020 & 0,018 & 1,125 & 0,268 \\
\hline (Q) Autoriza a alienação de bens do ativo não circulante & $-0,002$ & 0,009 & $-0,247$ & 0,806 \\
\hline (R) Autoriza a constituição de ônus reais & 0,014 & 0,014 & 0,982 & 0,333 \\
\hline (S) Autoriza a prestação de garantias e obrigações & 0,028 & 0,010 & 2,867 & $* 0,007$ \\
\hline (T) Escolhe e destitui os auditores independentes & $-0,098$ & 0,039 & $-2,487$ & $* 0,018$ \\
\hline
\end{tabular}

Notas: * Significantea 5\%; ** Significante a $10 \%$.

Sobre a intensidade dos parâmetros estimados (coeficiente B), partindo-se do pressuposto de que a existência de mulheres entre os membros do CA melhora a eficácia das decisões gerenciais das companhias, como indicado por Erhardt, Werbel e Shrader (2003), o coeficiente da variável B contrariou tal suposição, revelando que, em média, cada mulher a mais entre os membros do conselho reduz o ROA da companhia em 1,5 pontos percentuais (todos os percentuais citados a partir deste ponto têm como base o ROA ou o ROI).

Essa constatação contraria os achados de Erhardt, Werbel e Shrader (2003), quando observam que a literatura internacional sugere que a diversidade entre os membros dos CA impacta negativamente a dinâmica de grupo devido às divergências existentes quanto aos seus pontos de vista, contudo, melhora as decisões do grupo, uma vez que diferentes ideias motivam maiores discussões acerca das decisões a serem tomadas. Para os autores, as pessoas da mesma raça ou sexo são menos críticas das ideias umas das outras. Entretanto, tendo como base os resultados obtidos com a análise de regressão, nota-se que a ideia observada na literatura internacional sobre o impacto negativo da diversidade entre os membros nas dinâmicas de grupo faz sentido, embora não se possa dizer o mesmo sobre a constatação dos autores quanto à melhora das decisões do grupo, tendo em vista que o ROA tende a ser reduzido com o aumento da diversidade, principalmente de gênero.

Erhardt, Werbel e Shrader (2003) sugerem que, talvez, as mulheres e as minorias (hispânicos, asiáticos e negros norte-americanos) que atuam nos conselhos de administração possam ser mais eficazes em suas decisões. Os autores partem do pressuposto de que há um argumento comum de que mulheres e minorias possuem desvantagem de experiência de trabalho em relação aos seus homólogos brancos. Assim, eles precisam superar muitos de seus colegas homens e brancos a fim de conseguir uma promoção, o que sugere que seus desempenhos são gerados a partir de expectativas e padrões de qualificação mais elevados. 
No mercado brasileiro, tendo em vista que a presença do gênero feminino em cargos de alta administração é um fenômeno relativamente novo e em desenvolvimento, talvez as mulheres ainda não tenham alcançado essas expectativas ou padrões de qualificação, embora essa já seja uma realidade esperada.

Em relação à existência de membro estrangeiro nos conselhos de administração dos bancos $(\mathrm{F})$, os resultados sugerem que instituições que possuem estrangeiros entre seus conselheiros têm um ROA 4,7 pontos percentuais menor que aquelas nas quais o CA seja formado unicamente por profissionais brasileiros. Uma das explicações para esse fenômeno pode ser o conhecimento da influência cultural, que pode levar os brasileiros a tomarem decisões mais acertadas por conhecerem seu público alvo. Quanto ao prazo máximo de gestão dos eleitos para compor o conselho $(\mathrm{G})$, nota-se que companhias que possuem prazos máximos de gestão de três anos tendem a ter seu ROA reduzido em 3,4 pontos percentuais. Talvez a permanência dos membros por longos períodos tragam-lhes o conhecimento e a expertise necessária à boa gestão dessas companhias.

Por outro lado, nota-se que as empresas que possuem a maioria de seus conselheiros graduados na área de negócios $(\mathrm{H})$ tendem a ter um ROA maior em 2,8 pontos percentuais, o que chama a atenção, uma vez que a maioria das firmas investigadas revelou ter seus conselhos compostos por profissionais formados em áreas remotas à de negócios. Nesse contexto, Furiati e Luz (1996) observam que as funções dos administradores variam significativamente, assim como sofre a concorrência frequente de diversas categorias profissionais, tais como: engenheiros, advogados, sociólogos e até mesmo médicos, sendo possível encontrar tais profissionais ocupando cargos de gerência e direção. Ainda, segundo Bruère, Silva e Santos (2007), assume-se que os conselheiros, durante o processo de tomada de decisão, necessitam de conhecimentos relativamente abrangentes, principalmente acerca de Contabilidade e Finanças. Com isso, e considerando a significância dessa variável a 10\%, infere-se que a presença de profissionais com formação específica na área de negócios agrega valor ao desempenho financeiro.

Com relação às variáveis significativas referentes às competências atribuídas aos conselhos, nota-se que companhias que autorizam a prestação de garantias e obrigações a terceiros (S) estão propensas a terem o ROA aumentado em 2,8 pontos percentuais em relação àquelas que não autorizam a prestação de tais garantias. $\mathrm{E}$, ainda, empresas nas quais o CA escolha e destitua os auditores independentes (T) tendem a ter seu ROA reduzido em 9,8 pontos percentuais. Ademais, as outras variáveis (A, C, D, I, J, K, L, M, N, O, P, Q e R) não apresentaram significância estatística e, por essa razão, não foram alvo de análise. A variável A, quantidade de membros, não foi significativa, assim como no estudo de Erhardt, Werbel e Shrader (2003).

A segunda regressão analisou a relação das variáveis independentes com o ROI dos Bancos, também com nível de confiança de $95 \%$. De forma similar ao procedido na regressão anterior, não foi observada presença de autocorrelação entre os resíduos, pois o teste de Durbin-Watson revelou valor igual a 2,027 (dentro dos limites 1,54 e 2,46); não foi detectada a presença de heterocedasticidade; já a hipótese nula de não significância do modelo de regressão foi rejeitada $\left(\mathrm{F}_{\text {calculado }}>\mathrm{F}_{\text {tabelado }} ; 2,148>1,840\right.$, respectivamente), indicando significância estatística do modelo; e, a regressão apresentou um coeficiente de determinação de 0,742 , indicando que as variáveis contidas no modelo podem explicar $74,2 \%$ das variações observadas na variável dependente (ROI).

A partir dos resultados da segunda regressão, pode-se observar que 7 das 21 variáveis apresentaram significância estatística a 5\%, indicando influência sobre as variações observadas no ROI das companhias investigadas. As quatro primeiras são variáveis referentes às características dos conselhos: (i) quantidade de membros do gênero feminino, (ii) possui membro representante dos empregados, (iii) possui membro estrangeiro e (iv) prazo máximo 
de gestão de três anos. As outras três se referem às competências atribuídas aos conselhos: (v) fiscaliza a gestão dos diretores, examinando a qualquer tempo suas ações, (vi) autoriza a prestação de garantias e obrigações a terceiros e (vii) escolhe e destitui os auditores independentes. Além disso, duas variáveis foram significativas a 10\%, são elas: quantidade de membros e possui graduação na área de negócios, como pode ser observado na Tabela 5.

Tabela 5 - Resultado da regressão linear para a variável dependente ROI. 2008 - 2009

\begin{tabular}{|c|c|c|c|c|}
\hline Variáveis & $\begin{array}{c}\text { Coeficiente } \\
\text { B } \\
\end{array}$ & $\begin{array}{c}\text { Erro } \\
\text { Padrão }\end{array}$ & $\begin{array}{c}\text { Estatística } \\
\mathbf{t}\end{array}$ & $\begin{array}{c}\text { Signifi- } \\
\text { cância }\end{array}$ \\
\hline (Constant) & 0,209 & 0,065 & 3,227 & 0,003 \\
\hline (A) Quantidade de membros & 0,004 & 0,002 & 1,725 & $* * 0,093$ \\
\hline (B) Quantidade de membros do gênero feminino & $-0,022$ & 0,009 & $-2,335$ & $* 0,025$ \\
\hline (C) Possui membro do gênero feminino na presidência & $-0,015$ & 0,021 & $-0,724$ & 0,474 \\
\hline (D) Possui membro independente & $-0,011$ & 0,032 & $-0,352$ & 0,727 \\
\hline (E) Possui membro representante dos empregados & $-0,040$ & 0,015 & $-2,740$ & $* 0,010$ \\
\hline (F) Possui membro estrangeiro & $-0,061$ & 0,029 & $-2,086$ & * 0,044 \\
\hline (G) O prazo máximo de gestão é 3 (três) anos & $-0,055$ & 0,021 & $-2,642$ & $* 0,012$ \\
\hline (H) A maioria dos membros possui graduação na área & 0,041 & 0,021 & 1,986 & $* * 0,055$ \\
\hline (I) $\mathrm{O}$ estado civil mais comum entre os membros & 0,035 & 0,027 & 1,304 & 0,201 \\
\hline (J) Fixa a orientação geral dos negócios da companhia & 0,012 & 0,020 & 0,611 & 0,545 \\
\hline (K) Elege e destitui os diretores da companhia & $-0,015$ & 0,021 & $-0,700$ & 0,489 \\
\hline (L) Fiscaliza a gestão dos diretores & $-0,020$ & 0,010 & $-2,071$ & $* 0,047$ \\
\hline (M) Convoca a assembléia geral & $-0,021$ & 0,019 & $-1,077$ & 0,289 \\
\hline (N) Emite parecer sobre o relatório de administração & $-0,018$ & 0,019 & $-0,941$ & 0,353 \\
\hline (O) Emite parecer previamente sobre atos e contratos & 0,015 & 0,011 & 1,267 & 0,214 \\
\hline (P) Delibera sobre a emissão de ações ou de bônus & 0,023 & 0,023 & 1,008 & 0,320 \\
\hline (Q) Autoriza a alienação de bens do ativo não circulante & $-0,003$ & 0,012 & $-0,251$ & 0,803 \\
\hline (R) Autoriza a constituição de ônus reais & 0,016 & 0,019 & 0,871 & 0,390 \\
\hline (S) Autoriza a prestação de garantias e obrigações & 0,047 & 0,013 & 3,682 & $* 0,001$ \\
\hline (T) Escolhe e destitui os auditores independentes & $-0,145$ & 0,051 & $-2,848$ & $* 0,007$ \\
\hline
\end{tabular}

Notas: * Significante a5\%; Significante a $10 \%$.

Sobre a significância dos parâmetros estimados (coeficiente B), nota-se que, assim como observado na regressão anterior, a variável B indica que cada membro do gênero feminino a mais que integre o CA dessas empresas tende a reduzir seu ROI em 2,2 pontos percentuais. Retomando a discussão anterior sobre o papel da mulher nesses conselhos, atenta-se para a observação de Nielsen e Huse (2010) de que o aumento da atenção destinada às mulheres que compõem os conselhos de empresas tem apresentado novos desafios às pesquisas relativas à governança corporativa. Fundamentando-se nas teorias das diferenças de gêneros, os autores concluem que a proporção de mulheres na gestão está direta e positivamente associada ao controle estratégico do conselho. Além disso, sugerem os efeitos positivos que a presença das mulheres na gestão provoca sobre a eficácia do conselho, que poderiam ser comprovados através do aumento das atividades desenvolvidas e da diminuição do nível de conflitos dentro do CA. Contudo, os autores se limitam à discussão teórica, não trazendo evidências empíricas que comprovem seus argumentos, as quais são levantadas nesta investigação e que, pelo menos diante dos dados analisados, contrariam tais argumentos.

O coeficiente da variável (E) indica que a presença de membro representante das empresas reduz o ROI das empresas em 4,0 pontos percentuais. Já o coeficiente da variável "possui membro estrangeiro" (F) foi negativo e significante, indicando que os bancos que possuem em seus conselhos membros provenientes de outros países tendem a ter um ROI 
menor na proporção de 6,1 pontos percentuais em relação às empresas nas quais o CA é formado tipicamente por brasileiros. Com relação ao prazo máximo de gestão desses conselheiros, o coeficiente de determinação da variável $G$ sugere que companhias que possuem mandatos de até três anos têm um ROI 5,5 pontos percentuais menor que aquelas que ultrapassam esse limite legal. E, mais uma vez, o coeficiente da variável $\mathrm{H}$ revelou que companhias que possuem a maioria de seus conselheiros graduados em cursos da área de negócios possuem, em média, um ROI 4,1 pontos percentuais maiores que o de companhias com a maioria dos conselheiros graduados em outras áreas, a uma significância de $10 \%$.

Em uma investigação realizada junto a Bancos de varejo, Bantel (1993) identificou uma relação entre a natureza demográfica dos grupos de gestão de alto nível e a clareza estratégica daquelas instituições. Os achados do autor indicaram que uma maior educação e diversidade nas equipes de gestão conduzem às melhores tomadas de decisões estratégicas. Essa observação pode explicar o panorama observado neste estudo, em que, apensar de o aumento do número de conselheiros graduados na área de negócios ser um indicador de melhor desempenho financeiro, as firmas analisadas mantém a maioria dos conselhos formada por graduados em áreas remotas à de negócios. Entretanto, dentre os 28 Bancos analisados, todos apresentaram profissionais graduados na área de negócios, em maior ou menor número, assim como em outras áreas. Dessa forma, com base na afirmação de Bantel (2003), a mescla de profissões nos altos níveis de administração dessas instituições pode ser a explicação para o fenômeno observado.

Com relação às variáveis referentes às competências dos $\mathrm{CA}$, a variável relativa à "fiscalização da gestão dos diretores" (L) apresentou um coeficiente negativo e significante, indicando que companhias que atribuem a seus conselhos de administração a fiscalização de seus diretores tendem a ter um ROI menor na proporção de 2,0 pontos percentuais que aquelas que não atribuem tal competência. Dentre os 28 Bancos, cerca de $75 \%$ possuem essa competência determinada em seus estatutos. D acordo com Mclntyre e Murphy (2008), sob uma visão holística, o conselho possui um papel complexo, pois está sujeito à possibilidade de agir em interesse próprio, assim como em interesse da administração. Para os autores, esse papel trás consigo a necessidade de assegurar aos acionistas que o CA não se envolva com esse tipo de comportamento. Tendo em vista os recentes escândalos e fraudes envolvendo instituições bancárias no país, acredita-se que os CA's desses Bancos deveriam reservar maior atenção para a fiscalização das ações implementadas por seus diretores. Apesar disso, atentase para a observação de Murphy e Mclntyre (2007) de que o papel de condução que o CA deve ser capaz de desenvolver não se limita a ser um instrumento de coerção.

Ainda, o coeficiente de determinação da variável $S$ foi positivo e altamente significativo, indicando que instituições que autorizam a prestação de garantias e obrigações a terceiros tendem a ter um ROI superior na proporção de 4,7 pontos percentuais em relação às companhias que não determinam essa competência ao seu conselho de administração. E, por fim, empresas nas quais o CA escolha e destitua os auditores independentes (T) o ROI tende a ser 14,5 pontos percentuais menor que de empresas nas quais o CA não tenha essa atribuição. Ademais, as outras variáveis $(\mathrm{C}, \mathrm{D}, \mathrm{I}, \mathrm{J}, \mathrm{K}, \mathrm{M}, \mathrm{N}, \mathrm{O}, \mathrm{P}, \mathrm{Q}$ e R) não apresentaram significância estatística e, por essa razão, não foram alvo de análise. Da mesma forma, procedeu-se com a variável A que, apesar de significante a $10 \%$, apresentou coeficiente $0,4 \%$. No estudo de Erhardt, Werbel e Shrader (2003) esta variável não foi significante.

\section{CONCLUSÕES}

Este estudo, além de identificar as principais características e competências dos conselhos de administração dos principais Bancos brasileiros, buscou relacioná-las com seus desempenhos financeiros. Nesse sentido, realizou-se uma revisão na literatura internacional acerca do conselho de administração e de sua relação com a governança corporativa e o 
desempenho financeiro das empresas, procurando identificar a relação entre as características das companhias e dos conselhos com seus desempenhos financeiros. Além disso, buscaram-se trabalhos que abordam essa temática no mercado nacional, evidenciando as competências atribuídas ao conselho de administração de acordo com a legislação aplicável. Dessa forma, foram analisados os conselhos de administração e os desempenhos financeiros dos 28 Bancos integrantes desse segmento na Bolsa de Valores de São Paulo.

Seus principais resultados sugerem que, em geral, o cargo de conselheiro ainda é predominantemente masculino, tendo em vista que 94,1\% dos membros dos conselhos de administração dos bancos listados na BM\&FBovespa são homens. Além disso, pode-se observar que a presença das mulheres entre os membros do CA dessas empresas tem uma relação direta, embora negativa, com o desempenho financeiro dessas companhias. Contudo, essa constatação é vista como um fato inesperado, tendo em vista que diversos estudos internacionais atestam o contrário, relacionando a presença feminina nesses conselhos com o controle estratégico e a eficácia do CA, que poderiam ser comprovados através do aumento das atividades desenvolvidas e da diminuição dos níveis de conflitos dentro do conselho.

Uma explicação para essa divergência, talvez, seja a recente e ainda crescente participação das mulheres na gestão dessas companhias, ocupando cargos de altos níveis da administração. Com isso, observa-se que, apesar do notável crescimento da representatividade das mulheres no mercado de trabalho nos últimos anos, inclusive em altos cargos administrativos, o gênero feminino ainda amarga a discriminação profissional, principalmente aqui no Brasil, o que acaba resultando, geralmente, em menores salários ou maiores esforços para galgar cargos de direção.

Quanto às relações estabelecidas entre as características e competências dos conselhos de administração com o desempenho financeiro das companhias, observou-se que 7 das 21 variáveis se mostraram significativas ao nível de $5 \%$ e influentes com relação ao ROA e ao ROI, os quais representaram esse desempenho. Dentre as variáveis características do CA, destacaram-se: (B) a quantidade de membros do gênero feminino, (E) a presença de membro representante dos empregados, $(F)$ a existência de membro estrangeiro e $(\mathrm{G})$ o prazo máximo de gestão dos membros. Dentre as variáveis referentes às competências desse conselho, destacaram-se: (L) a fiscalização da gestão dos diretores, (S) a autorização e prestação de garantias e obrigações a terceiros e (T) escolha e destituição dos auditores independentes. Conclui-se que tais variáveis possuem o poder de influenciar o desempenho financeiro dos bancos, seja de forma positiva ou negativa. Contudo, atenta-se que o fato de as empresas incluírem nos textos de seus estatutos sociais as competências do CA não garante que tais ações sejam efetivamente implementadas pelos membros desses conselhos.

Por fim, é indispensável observar que a pesquisa ora realizada foi restrita ao grupo de companhias de capital aberto que compôs a amostra, durante os exercícios de 2008 a 2009. Assim, os resultados aqui apresentados representam apenas um recorte da realidade em questão, não possuindo a intenção de serem colocados como respostas definitivas ao problema investigado. Todavia, observa-se que, considerando seus achados e a escassez de estudos com essa amplitude, tais limitações não o invalidam. Nesse sentido, recomenda-se, para futuros estudos, que seja expandida a amostra analisada e utilizadas novas metodologias de análise e relacionamento desses dados a fim de se verificar novas tendências.

\section{REFERÊNCIAS}

ANDERSON, R. C.; SATTAR, A. M.; REEB, D. M. Board characteristics, accounting report integrity, and the cost of debt. Journal of Accounting \& Economics, v. 37, n. 3, p. 315-342, 2004. http://dx.doi.org/10.1016/j.jacceco.2004.01.004

ASSAF NETO, A. Finanças corporativas e valor. 3. ed. São Paulo: Atlas, 2007. 
BAIMAN, S. Agency research in managerial accounting: a second look. Accounting Organization and Society, v. 15, n. 4, p. 341-371, 1990. http://dx.doi.org/10.1016/03613682(90)90023-N

BANTEL, K. Strategic clarity in banking: role of top management-team demography, $\begin{array}{llllll}\text { Psychological Reports, } & \text { v. 73, p. } & 1187-1203, & 1993 .\end{array}$ http://dx.doi.org/10.2466/pr0.1993.73.3f.1187

BARNEY, J. B.; HESTERLY, W. Economia das organizações: entendendo a relação entre as organizações e a análise econômica. In.: CALDAS, M.; FACHIN, R.; FISCHER, T. (orgs.). Handbook de Estudos Organizacionais: ação e análise organizacionais. São Paulo: Atlas, 2004.

BERGHE, L. A. A. V. D.; LEVRAU, A. Evaluating boards of directors: what constitutes a good corporate board? Corporate Governance, v. 12, n. 4, p. 461-478, 2004. http://dx.doi.org/10.1111/j.1467-8683.2004.00387.x

BOLSA de Mercadorias \& Futuros da Bolsa de Valores de São Paulo (BM\&FBOVESPA). Governança corporativa. Disponível em: <http://www.bmfbovespa.com.br/ciaslistadas/consultas/governanca-corporativa/governanca-corporativa.aspx?Idioma=pt-br $>$. Acesso em: 06 jan. 2011.

BRASIL. Lei $\mathbf{n}^{0}$ 6.404, de 15 de dezembro de 1976. Dispõe sobre as Sociedades por Ações. Disponível em: <http://www.planalto.gov.br>. Acesso em: 25 dez. 2010.

BRUÈRE, A. J.; SILVA, W. M.; SANTOS, J. F. Aspectos da governança corporativa de empresas listadas na Bovespa: um estudo exploratório sobre a composição e perfil dos conselhos de administração. BASE - Revista de Administração e Contabilidade da Unisinos, v. 4, n. 2, p. 149-159, maio/ago. 2007.

CARTER, C. B.; LORSCH, J. W. Back to the drawing board: designing corporate boards for a complex world. Harvard Business School Publishing Corporation, 2004.

COASE, R. H. The nature of the firm. Economica, New Series, v. 4, n. 16, p. 386-405, 1937. http://dx.doi.org/10.1111/j.1468-0335.1937.tb00002.x

DUTRA, M. G. L.; SAITO, R. Conselhos de administração: análise de sua composição em um conjunto de companhias abertas brasileiras. RAC. Revista de Administração Contemporânea, v. 6, n. 2, p. 9-27, maio/ago. 2002. http://dx.doi.org/10.1590/S141565552002000200003

ERHARDT, N. L.; WERBEL, J. D.; SHRADER, C. B. Board of director diversity and firm financial performance. Corporate Governance, v. 11, n. 2, p. 102-111, 2003. http://dx.doi.org/10.1111/1467-8683.00011

FINKELSTEIN, S.; HAMBRICK, D. C. Strategic leadership: top executives and theireffects on organizations. Australian Journal of Management, v. 22, n. 2, p. 221-224, 1997. http://dx.doi.org/10.1177/031289629702200205

FURIATI, A. E.; LUZ, T. R. O perfil gerencial e o papel do administrador sob o ponto de vista das organizações. In: EnAngrad, 7., 1996, Florianópolis/SC. Anais... Florianópolis: ANGRAD, 1996.

GUJARATI, D. N. Econometria básica. 4. ed. Rio de Janeiro: Elsevier, 2006.

JENSEN, M. C. The modern industrial revolution, exit, and the failure of internalcontrol systems. The Journal of Finance, v. 48, n. 3, p. 831-880, 1993. http://dx.doi.org/10.1111/j.1540-6261.1993.tb04022.x 
JENSEN, M. C.; MECKLING, W. H. Theory of firm: managerial behavior, agency cost, and ownership structures. Journal of Financial Economics, v. 3, n. 4, p. 305-360, 1976. http://dx.doi.org/10.1016/0304-405X(76)90026-X

KÖCHE, J. C. Fundamentos da metodologia científica: teoria da ciência e prática da pesquisa. 14. ed. Petrópolis: Vozes, 1997.

LIPTON, M.; LORSCH, J. A modest proposal for improved corporategovernance. Business Lawyer, v. 48, n. 1, p. 59-77, 1992.

MARTINS, H. C. Governança corporativa em cenário de mudanças: evidências empíricas das alterações dos atributos, papéis e responsabilidades do conselho de administração das empresas brasileiras. 2004. 256f. Tese (Doutorado em Administração) - Universidade Federal de Minas Gerais, Belo Horizonte, 2004.

MARTINS, H. C.; RODRIGUES, S. B. Atributos e papéis dos conselhos de administração nas empresas brasileiras. RAE. Revista de Administração de Empresas, Edição Especial, p. 23-35, 2005.

MCLNTYRE, M. L.; MURPHY, S. A. Board of director performance reporting. Corporate Governance, v. 8, n. 2, p. 165-178, 2008. http://dx.doi.org/10.1108/14720700810863797

MONKS, R.A.G.; MINOW, N. Corporate Governance. 2. ed. Cambridge, MA: Blackwel Business, 2001.

MOURA, G. D.; BEUREN, I. M. Conselho de administração das empresas de governança corporativa listadas na BM\&FBovespa: análise à luz da entropia da informação da atuação independente. Revista de Ciências Administrativas, v. 13, n. 29, p. 11-37, jan./abr. 2011.

MURPHY, S. A.; MCLNTYRE, M. L. Board director performance: a group dynamics perspective. Corporate Governance, v. 7, n. 2, p. 209-224, 2007. http://dx.doi.org/10.1108/14720700710739831

NIELSEN, S. HUSE, M. The contribution of women on boards of directors: going beyond the surface. Corporate Governance, v. 18, n. 2, p. 136-148, 2010. http://dx.doi.org/10.1111/j.1467-8683.2010.00784.x

PUGLIESE, A.; BEZEMER, P. J.; ZATTONI, A.; HUSE, M.; BOSH, F. A. J. V. D.; VOLBERDA, H. W. Boards of directors' contribution to strategy: a literature review and research agenda. Corporate Governance, v. 17, n. 3, p. 292-306, 2009. http://dx.doi.org/10.1111/j.1467-8683.2009.00740.x

SHLEIFER, A.; VISHNY, R. W. A survey of corporate governance. The Journal of Finance, v. 52, n. 2, p. 737-783, 1997. http://dx.doi.org/10.1111/j.1540-6261.1997.tb04820.x

SHRADER, C.; BLACKBURN, V.; ILES, P. Women in management and firm financial performance: an exploratory study. Journal of Managerial Issues, v. 9, p. 355-372, 1997.

SILVA, W. M.; MAGALHÃES FILHO, P. A. O. Existe alguma associação entre governança corporativa e diversificação na firma? Um estudo empírico com indústrias brasileiras. In: EnAnpad, 28., 2004, Curitiba/PR. Anais... Rio de Janeiro: ANPAD, 2004.

VALOR ECONÔMICO. O papel de cada órgão no PanAmericano. Disponível em: $<$ http://www.valoronline.com.br/impresso/investimentos/119/343555/o-papel-de-cada-orgaono-panamericano>. Acesso em: 20 dez. 2010.

VIEIRA. S. P.; MENDES A. G. S. T. Governança corporativa: uma análise de sua evolução e impactos no mercado de capitais brasileiro. Organizações em Contexto, v. 2, n. 3, p. 48-67, 2006. 
VOLPIN, P. F. Governance with poor investor protection: evidence from top turnover in Italy. Journal of Financial Economics, v. 64, n. 1, p. 61-90, 2002. http://dx.doi.org/10.1016/S0304-405X(02)00071-5 